\title{
Virtual Reality City as a Model for the Sustainability of Urban Life in the Built Environment
}

\author{
Ahmed Abdel Moneim Al Qattan* \\ Faculty of Engineering, Department of Architecture, Al-Azhar University, Egypt \\ Received 03 Sept 2019, Accepted 04 Nov 2019, Available online 05 Nov 2019, Vol.9, No.6 (Nov/Dec 2019)
}

\begin{abstract}
The sustainability of urban life is the creation of a state of balance and the re-formulation of the environmental and economic determinants and objectives. The sustainability of urban life combines between the sustainability of natural resources, particularly water and energy, and the sustainability of technology, finance, institutional and community. The study focuses on the virtual reality city and its advanced technologies provided to the citizens of the built environment. Therefore, the research study is based on the use of modern technologies provided by virtual reality which are interactive platforms that enable the citizen to move in a three-dimensional form to give a new dimension to communication between him and products, companies and information. It opens a new world of opportunities such as three-dimensional ordering lists and three-dimensional networks and the movement of the human body and the cognitive ability of the citizen and above all a more attractive and sensory and emotional experience, and takes care to understand the type of spaces that the community cares to live and the purposes that can be provided by these spaces of relaxation or Entertainment or Science. And this is to show new spaces for discussion or exceptional scenarios where you can meet with friends. In this case, convergence platforms such as Converge and Second Life, which are interesting for new Architectural and urban implications. In view of the challenges of the urban planning profession and the undeniable natural resource crisis, and the renaissance of virtual reality, it is time to get rid of what we have learned and create new spaces for our time. As urban developers, we see the opportunity in virtual reality to serve society and the built environment by codifying the concept of virtual reality city of technologies to reach the best sustainable urban environment. The methodology of the research study is based on an inductive method to introduce the concept of virtual reality, virtual worlds, virtual environment, and second life, and then to address the most important tools used in its applications and deal with them to get out in the field of architecture and urbanization and to benefit from them within the analytical approach by developing the virtual city services provided by the virtual reality city And assess the urban sustainability components of the Virtual Reality City to reach a model of a virtual reality city that is sustainable for urban life in the built environment to emerge from the net And recommendations that reflect the possibility of planning a virtual reality city and assessing its achievement of elements of sustainability of urban life in the built environment.
\end{abstract}

Keywords: Virtual worlds, Virtual environment, Virtual reality, Second life, Virtual reality city, Sustainability , Sustainability of urban life, Stereoscopic vision

\section{Introduction}

Planning is defined as an approach and a method of logical and rational thinking related to the portrayal of a certain reality in the future and then the development of all means and scientific foundations to achieve, and from this definition began to develop the central points to reach the desired goal in the subject is the answer to the main question, Is it time to plan the first virtual reality city?

To answer this question, it is necessary to reach answers to several questions:

*Corresponding author is working as Assistant Professor (ORCID ID: 0000-0000-0000-0000); DOI: https://doi.org/10.14741/ijcet/v.9.6.2
First, what is the virtual reality and its concepts and tools that will be used in the visualization of the virtual city planning?

Second: What scientific applications have already been applied in our lives in the field of virtual reality for the service of architecture and construction?

Third, can these applications be the nucleus of virtual city planning?

Fourth: What are the pros and cons that we can monitor when implementing the virtual reality city? What are the indicators of the sustainability of urban life in the built environment of the virtual reality city?

Fifth: Can you imagine the layout of this city and its classification functionally? 


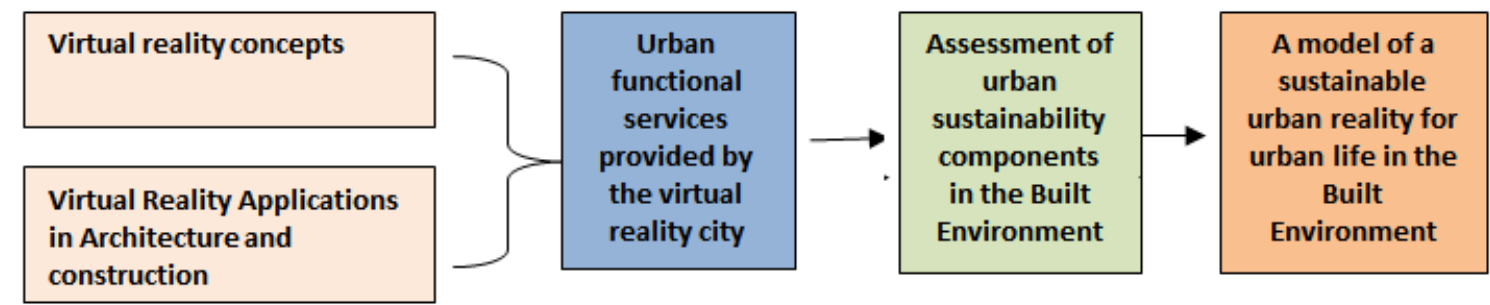

Figure 1 Methodology of the research study

To answer these questions, a research methodology was developed as follows:

The research methodology is based on an inductive approach to introduce the concept of virtual reality, the virtual worlds, the virtual environment, and the second life, and then address the most important tools used in its applications and deal with them in the field of architecture and urbanization. It will assess the urban sustainability components provided by the virtual reality city in order to reach a model of a sustainable virtual city for urban life in the built environment as shown in Figure (1).

\section{Scientific terms and concepts:}

\subsection{Virtual worlds}

Virtual worlds are defined as virtual 3D programs. The user can create virtual characters such as avatars, build and design buildings and models, perform various kinds of activities, and learn and communicate with other people from around the world.

\subsection{Virtual environment:}

The interactive 3D world is a kind of online community that takes the form of simulating the real environment based on the computer. The user in this environment can interact with others, use and create entities, and aim to allow the user to live and interact in them. The virtual world is interactive because the user takes Personal graphic avatar visible to others.

\subsection{Second Life}

A website that relies on the use of the multi-user virtual environment (MUVE) and is used in many areas, including education and its address is http://secondlife.com/. It is a fictional virtual world game launched three-dimensional on the Internet in 2003 as a second life parallel to the human life we live on the planet, the people of this world are today millions of people from all over the world, living, selling and buying. They can buy land, islands, build houses and look for entertainment and happiness. Wikipedia, a virtual world of three-dimensional virtual worlds on the Internet that combines the best aspects of Internet-based training with traditional classrooms and every personality in this world that reflects a true personality in the real world and who has chosen (Avatar).It is a fictional character represented in this world, which is the field of many different institutions of commercial, industrial and military and educational institutions located on the ground to find a place within which it can exercise its activities under the use of Modern techniques used in the third generation of the web generation that uses the three-dimensional technology in the development of sites.

\subsection{Virtual Reality}

It can be easily defined as an embodiment of the real(Imaginative with advanced technological means) reality, but it is not real, giving us infinite possibilities of light, extension, sound, sensation, vision and emotional turmoil as if we were in physical reality.

\subsubsection{Virtual reality technology}

Virtual reality is based on a combination of technologies and techniques that work together to produce its components. Each technology system used in virtual reality provides a different perspective for dealing with the virtual world, each trying to make things easier to interact between the user and the computer. But they meet together as means to transform information into sensations and cognitive experience.

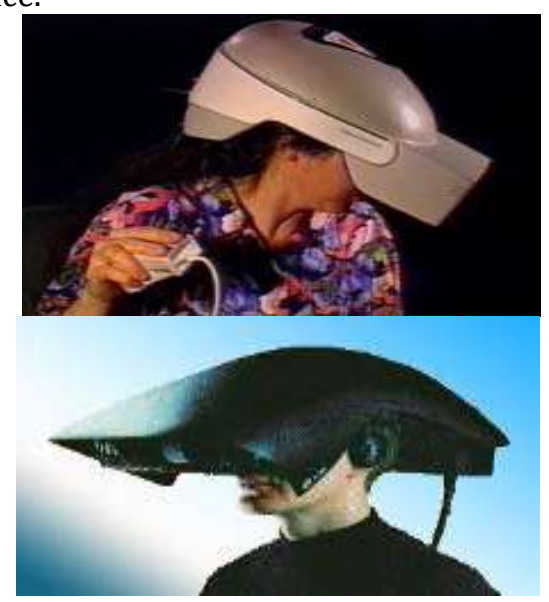

Figure 2 Some virtual reality devices are large to the degree of foreclosure

In the late 1960s, Myron Krueger, nicknamed "the father of Virtual Realism," began to create types of interactive environment in which a user moves without a disabled device (Figure 2). Kruger's virtual 
reality is virtual realism under the principle of "Comeas-you-are-VR". Kruger's cameras used receivers to highlight the user's body so that he can interact with computer-generated images and allows hands to manipulate graphics on a screen, this format is text or images. The process of interaction between computer and human without covering the body input load is left to the computer and become free movements of the body as inputs on the computer read. The cameras monitor the movement of the body and the computers by installing user movements with an artificial environment.

In the site Kruger called Video place, there are a number of people in separate rooms interactively interacting with each other. While sound and light techniques respond to people's movements by lighting tubes with phosphorescence or artificial sounds. Kruger also built another environment called Psychic Space, which allows participants to interactively explore a maze in which every foot step fits into a certain rhythm of music, all of which occur through live video images that can be moved and managed without taking into account the traditional rules of cause and effect.

More than one user can subscribe to the same imaginative or virtual world, by using several computers connected to each other on a network, and users can see each other and interact and compete. The sharing of virtual worlds is generally called shared virtual worlds or net worked VR.

Scientists are looking to introduce a sense of smell and taste into the imaginary world, which will be in the near future. Virtual reality technology systems simply share a common mission of creating a stereoscopic and immersive vision. Induction can be achieved in many different ways, united by one thing in common, which is to reduce all that users can see to computer simulations only. When you look at the computer screen, you see many other things around you, because in addition to your normal vision, you have the "surrounding" view of being able to see things from the side of the room away from the corner you are looking at. Because of them, you - involuntarily - devote a great deal of your mental power to the treatment of what is around you, which makes you wonder as you want to focus on it. Many virtual machines work in such a way that your peripheral vision is completely occupied by the image created by the computer and not by anything else. The better the device, the more immersive you feel, allowing your mind to focus entirely on the virtual world. Although - contrary to popular belief - it is not necessary to see a stereogram to feel integrated into the landscape. The sense of integration is enhanced by the stereoscopic rendering that makes images look three-dimensional and with the help of stereoscopic vision; the sense of integration can be so strong that one loses the ability to distinguish between what is real and what is just a picture.

2.4.2 Augmented Reality

They are used to display realistic environments with virtual objects and elements and allow the user to interact with them in a way that does not differentiate between real and virtual. This genre was used in the Egyptian theater for directors who saw that the whole stage of the theater limited the art within limited molds and resorted to the so-called movie theater. Which virtual realism develops strongly and gives it the ability to convey reality to the viewer better. The elements of the environment can be represented here by using holography techniques that turn people into a part of an open reality that is, entering them into a virtual theater instead of being trapped inside. NASA researchers say it will be used as a new means of communication between scientists. A scientist at a remote location can display his image on the walls of a scientific laboratory and on the walls of a scientific conference hall.

The principle of the generation of holographic forms is based on the dispersion of optical rays to create a stereogram. The British scientist Denis Gabor, who was awarded the Nobel Prize for work in this field first developed in 1947, and the first holographic images emerged with laser and computer development. Researchers and Ames Research Laboratories are developing holographic halls. NASA is studying the process of creating "holograms" in many of its labs and is considering licensing companies, especially those in virtual reality. These projects are still in the pipeline as researchers hope to erect holographic hubs in the near future.

\section{Virtual Reality Applications}

What can happen by using virtual reality is limited only by our imagination, and no area of life can be replicated. "I hope that virtual reality will have a role not only in education and the facilitation of life but also in the creation of new forms of art, the creation of new ways of cultural expression, the discovery of new forms of beauty and the creation of new ways of rapprochement among people," he said.

Astronauts can use virtual reality to train on space missions. Police officers can deal with dangerous situations before they face them, develop and test the different scenarios. Pilots can practice air maneuvers and prepare for emergencies without risk or damage. There is no doubt that there are no limits to virtual reality applications. The following are some of the highlights of these applications:
- Training
- Medical Practice
- Education
- Retail \& Marketing
- Military
- Data Visualization
- Engineering
- Entertainment
- Construction
- Collaborative Virtual 
The following are some of the most important applications:

\section{A-Training Systems}

This is one of the prominent areas of virtual reality applications. Training here means giving the user the ability to handle operations frequently without the risk on him or his environment. Specialized companies have been able to build training systems on real-time hardware simulators to train and test the user before training on the real equipment. These systems include Flight Simulators, which are similar to the cockpit of the pilot and show the correctness of all indicators, signals and sound and optical effects, and can train on the implementation of flight and change the height, speed and maneuver in the atmosphere similar to the real plane in the basic training period, While maintaining the real equipment so that it does not begin to deal with them and use them only after having obtained an appropriate amount of expertise on flight simulation systems. In addition, archaeological excavations using virtual reality cannot damage the archaeological sites. Virtual reality techniques are heard using different strategies and methods without significant physical or moral costs. There are similar systems to simulate driving cars and to work on complex machines, whether in factories or others.

\section{B-Educational Applications}

Virtual reality can represent the magnetic and electric fields, fluid flow, molecular models of various materials, the creation of mathematical systems and the flow of information in interactive systems with the user, and also more than one user can participate in displaying the functions of things and their behavior and manners. This type is a clear addition to education techniques.

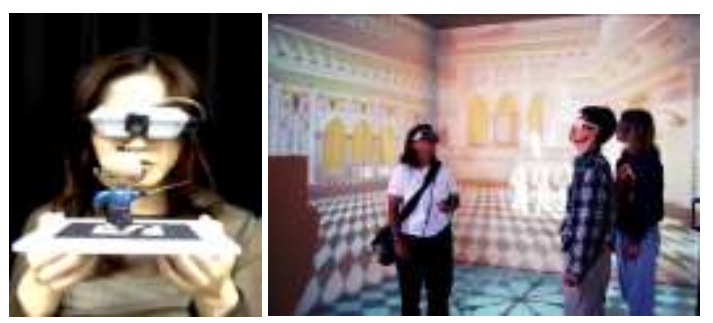

Figure 3 Remote presence with objects or in places such as museums or archaeological sites

Educational applications also include virtual visits and simulations of things that students may find difficult to access. Virtual Museums allow you to tour a museum with all its wings and possessions, both remotely and in close proximity, and see the general shape or precise details of the exhibits in locations that are hard to reach. They can also watch events related to these sites, such as historical battles, and allow them to wonder what would have happened if they had. As shown in Figure (3).

"The brain works to connect new information with new stimuli. The problem with school classrooms is that stimuli and incentives remain the same despite the change of information, which is why many children do not like school and consider it boring," Laniere explains. . One example of these intriguing applications is that projects aimed at reconfiguring ancient civilizations combine all available historical information, including information on the atmosphere, plants and animals that existed at the time, and then allow students to visit them. For example, students can visit the ancient civilization of Egypt and travel between the pyramids and see the historical facts that accompanied the establishment. There are also applications to roam inside the human body through the circulatory system and explore the heart and nervous system, or visit the Antarctic or the jungles of Africa or the era of dinosaurs. These experiments are usually immersed in a helmet that captures the user's view from all angles and monitors the movement of the head. The images are instantly adjusted as they move, and the user sees events as a part of them.

\section{C-Entertainment Applications}

They include virtual art galleries, virtual titles, theaters, theaters and virtual cinema. Some even admit that virtual reality as an independent type of art has its own characteristics. In the field of visual media, the companies that produce television programs and films rely heavily on the virtual reality in the design of advertisements, program introductions, publications, films and others. In the film industry, virtual reality provides the ability to build a three-dimensional world whether this world is realistic, imaginary or abstract. This world includes the construction of systems such as buildings, backgrounds, trees, forests, machines, rivers, sailors, ships, planes, people, statues, simulation of crime and so on. All these objects can be animated by virtual reality, and the interaction between people and others can also be simulated, making virtual reality very powerful in film making.

\section{D- Scientific Visualization}

Where it is possible to enter abundant information for the computer on a specific subject and a fictional diagram of the subject is envisaged as in the case of celestial bodies and the shape of galaxies and others. Molecular models that can be a three-dimensional stereogram of complex compounds, especially protein compounds.

Virtual reality is also used in meteorology, where scientists monitor weather data such as temperature, humidity and wind movement and direction, feed it to the computer to analyze it, create three-dimensional representations of the weather system in that region, and produce predictions of the changes that are expected to occur. 


\section{E-Collaborative Virtual}

Virtual Collaborative Virtualization allows users to interact together in a virtual world that represents an environment. Creating virtual communities that some believe may be a substitute for existing states and political systems. In such applications, scientists see the importance of intercultural understanding and dialogue. Similar experiences have allowed students from conflicting countries to get to know each other. Perhaps these methods of simulation contribute to helping children to imagine better ways to solve the problems they inherit from the world of their parents.

The degrees of indulgence vary in the supposed reality (the feeling that you are surrounded and integrated). They do not allow much interaction like 3D movies where 3D glasses play a role in displaying different images for each eye. But indulging in the scene is most often on the screens of the very large IMAX movie theaters that occupy every area of your vision.

The movie Sky ride, which flies you on a terrific aerial tour over New York, is considering another example of a non-interactive experience, but it adds another sense to the viewer's experience: motion, the seats moving in this movie with the movement of the screen simultaneously. One of the film's scenes says: "I did not take a deep breath and I flew among the skyscrapers in New York and I almost bumped into one of them and screamed out of fear, then ordered them with all skill. I could not convince myself that this was not a real reality.

At present time, there are many virtual reality applications ranging from Internet-based services to the PC to visualize movement in different environments such as buildings and cities, and finally the usual applications in the world of technology, science and space programs (training in a virtual environment) Air and gravity capsules.

Virtual reality is applicable in many different areas. of course, we have a significant role in the entertainment industry in video games and cinema, as well as in medicine, biotechnologies, engineering design, design and marketing of consumer products. A variety of virtual reality technology is now being used in games, product and sales presentations, as well as in flight simulations, driving, and even space stations.

\section{F- Medical Applications}

Dr. Brad Ford Wood, the American scientist specializing in the use of radiation energy therapy, said that virtual reality technology helps doctors perform many operations as well as it provides a safe and painless way to diagnose many diseases. He said that the technology allows doctors to experience threedimensional surgery before conducting a human body. It also helps in determining the optimal treatment method as shown in Figure 4.

Other medical reports indicate that people who are in a state of fear of flying may soon be overwhelmed by the use of virtual reality technology. Psychologists in Georgia, the United States, are currently developing a device in which the computer plays the primary role.
Dr. Larry Hodges of the Georgia Institute of Technology explains that virtual reality is being used to help people who suffer from phobias because they are more efficient, less expensive and safer. During the trials of the treatment of those who are terrified of air travel, the patient uses a virtual reality headrest that simulates the view outside the window of the aircraft The program also realistically simulates takeoff, flight and landing operations in clear or turbulent weather. Hodges says we can also simulate sounds, which sometimes raise the patient's fears. The system has many advantages in its view that it does not waste time therapists, for example, to go to the airports to meet patients, and in the real plane will not be able to ask the doctor to take off and landing several times.

For more than three decades, the science fiction film "The Wonderful Journey," in which the micromachine has appeared to subtle volumes, has been shown. This dream has haunted scientists and researchers, the last of which is a group of researchers in North Carolina who tried to make the same impact in practice. Instead of deflation, they magnified images of minutes, particles and objects growing in zero, such as bacteria and viruses, to sizes up to the size of the football field. They were able, through advanced techniques, to see scenes in a three-dimensional nature and interact with them.

A new machine was built in the Department of Physics at the University of North Carolina called "Nano Manipulator". The latest technology in the world was used today to create this device. This modern machine has enabled scientists to swim in an infinitely small world by wearing a special telescope. "This device feels you're flying between molecules and makes chromosomes look enormous in the size of a mountain range," says a University of Iowa professor after testing the nanometer.

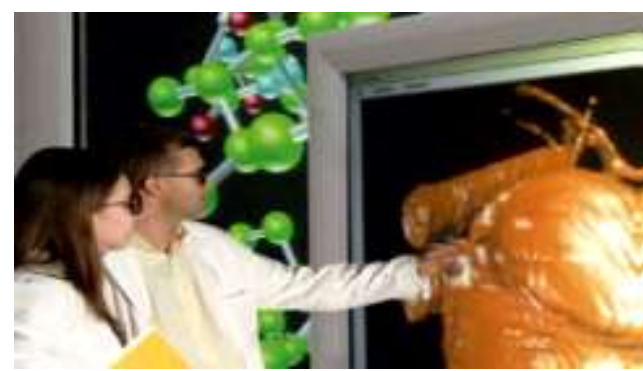

Figure 4 Anatomy of the heart muscle by default on a large screen

Virtual reality technology offers unprecedented solutions that may change the way doctors work in the future. Dr. Mark Whitehead, professor of anatomy at the University of California, said: "The interest in computer use to teach anatomy began about 20 years ago. However, the development of real 3D graphics requires a large computer capacity and to very sophisticated data, some doctors are currently using images and computer technology to see the patient's 
organs instead of taking simple pictures X-ray or perform an exploratory surgery.

Researchers at the University of Illinois, Jahn, built a large display called Immersadesk, which is connected to a Silicon Graphics computer that tracks the movement of the head of any individual standing in front of his screen wearing a specially designed telescope that forms part of the device. When moving, the person using the telescope can focus on different parts of the three-dimensional image on the screen. Experts say this computer-aided technology is not intended to replace traditional medical education tools, such as autopsies, but there are real benefits, such as being much less expensive to train doctors. Some say the use of models to perform virtual surgery will reduce many risks, such as the assistance provided by flight simulators to pilots. Dr. Richard Stava, professor of surgery at Yale University, who is interested in emerging surgical technologies and medical education, expects future surgeons to perform hypothetical operations prior to obtaining the practice permits from the Medical Association. Other institutes, including the Human Simulation Center at the University of Colorado, have moved from virtual reality to actual surgery. Karl Raining, along with other researchers there, is developing a surgical device that gives the surgeon the feel of the real scalpel as he cuts the meat. "The goal is to make the anatomy so close to the truth that the surgeon will forget that he is working with a computer," he says.

\section{G- Military Applications}

The US Army developed by Flight Simulators, and developed it for a long time. It has become one of the most important training methods for aviation in civilian and military types, and the military depends entirely on it to refine the skills of its soldiers and to achieve the highest readiness and maximum alertness in combat.

Today, the American soldier is trained on most modern weapons, chasing his enemies, and fighting them without breaking a position. It can learn from its mistakes to reach the highest level of combat readiness, without any serious consequences from training. Simulators provide hundreds of millions of dollars for practical training. The US military is now seeking to take all the scientific advances to increase its technical superiority and deepen the technical gap. And the armies of the world combined to preserve its uniqueness. The new research resulted in the birth of the first virtual reality theater, consisting of 3 projectors, a circular panoramic screen with a degree of curvature up to 180 degrees, and equipped with a high-capacity audio system of 3000 watts, Agile capabilities Shake used in the latest cinema showroom. And introduced the first training program based on this technology before the September 11 attacks several months. This internship test is placed on the responsibility site and tests its practical abilities to act in this position. The program, which is equipped with the highest technology available in the virtual reality world, is tested by the trainee's decision-making and practical implementation steps to solve the problem. The program provides a tangible reality that almost matches the actual location of the events, and enables the trainee to act freely as shown in Figure (5).
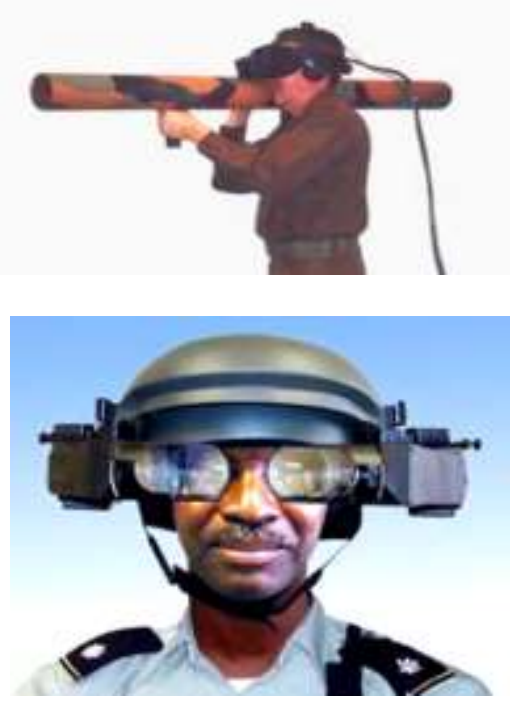

Figure 5 Military training on new weapons

Three weeks before the events of September 11 in New York and Washington, scientists began to think that these events would accelerate the emergence of new technologies that would play an important role in America's war against what they called "fight against terrorism", especially in the areas of planning, training, And control of wars against hostile groups. US military experts are currently relying on the latest technologies developed by the Institute of Creative Technology LCT, in collaboration with military experts and computer scientists at the University of South Carolina and the scriptwriter in Hollywood; to train its soldiers to act wisely in the most difficult combat situations, The most complex, especially the war in Afghanistan and Iraq.

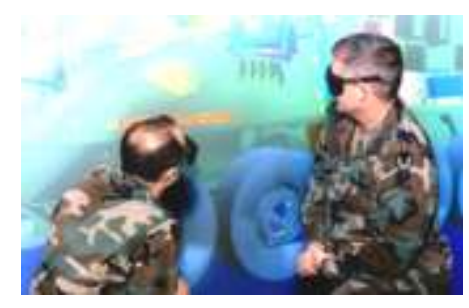

Figure 6 Design of military vehicles commensurate with the circumstances of each battle

Before the war on both the people of Afghanistan and Iraq, the US Department of Defense released a new training ground to prepare for the planned war against terrorism. A group of military commanders sat in front of the large screens following a mock battle between the US military and Taliban forces in Afghanistan. In 
which Afghan fighters organize bloody fighting in cities, caves and valleys, while US aircraft bombard their positions and places of residence. Strategy experts attempt to invent unconventional scenarios, guerrilla warfare, and develop a variety of possible scenarios as shown in Figure 6.

Prior to the occupation of Iraq, a number of leaders of the four US military bodies, military officers and former diplomats were assigned to participate in war games in cooperation with computer-simulated affairs to determine the most realistic scenarios to be applied in their war against Islam in Iraq. It is worth mentioning that these virtual exercises have taught the war planners of the US Department of Defense difficult lessons for the forest, as a result of the nature of the war is not familiar to the army for the first time, and did not succeed all the possibilities of the US military and technology and weapons long-range to reduce the number of wounded American soldiers through these Workouts, and presumed injuries were significant in all proposed scenarios.

US military commanders acknowledge the difficulty of predicting the real reaction of the resistance soldiers. Army commanders also acknowledge that superior tactical capabilities, sophisticated weaponry and intelligence capabilities for US-based US forces can do little to fight hideouts in caves and mountains with rugged mountainous terrain in Afghanistan; or street fighting by fighters in the streets of Iraqi cities where no There is a way to attack without heavy casualties in American soldiers.

\subsection{Urban Services Center of the virtual city}

After reviewing the virtual reality applications, the search starts step by step to create a different urban service center for the virtual reality city that you can provide to the citizens inside it as follows: As shown in Figure (7)

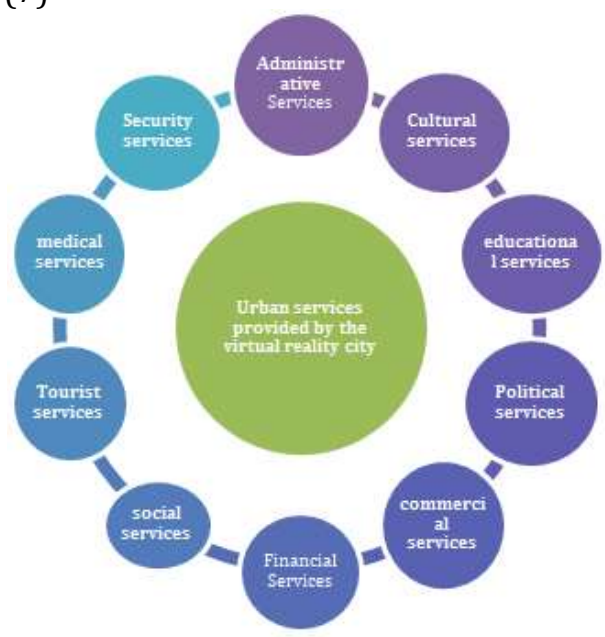

Figure 7 Diagram showing the distribution of urban services provided by the virtual reality city by the researcher

\subsubsection{Urban services for virtual reality city}

Table 1 Analytical description of the urban services of the virtual reality city shows a discharge from the researcher

\begin{tabular}{|c|c|c|c|}
\hline Series & Urban services & $\begin{array}{l}\text { Analytical description of the urban service provided by } \\
\text { the virtual reality city }\end{array}$ & cal examples \\
\hline 1 & $\begin{array}{c}\text { Services and } \\
\text { administrative } \\
\text { activities }\end{array}$ & $\begin{array}{l}\text { Virtual Reality City meets the needs of service users by } \\
\text { receiving applications using virtual reality and virtual reality } \\
\text { tools at any time, and then the service provider sends the } \\
\text { delegate, whether human or robot, to meet the needs of the } \\
\text { user. Which is already taking place in Dubai's administrative } \\
\text { and industrial services by sending robots to repair what might } \\
\text { happen in emergency water and electricity networks and also } \\
\text { in meeting the daily needs of its citizens in order to reduce } \\
\text { congestion and save time and effort for its citizens. }\end{array}$ & \\
\hline 2 & $\begin{array}{l}\text { Services and } \\
\text { cultural and } \\
\text { scientific } \\
\text { activities }\end{array}$ & $\begin{array}{l}\text { Providing services and cultural and scientific activities } \\
\text { through the virtual theater. There are also virtual scientific } \\
\text { laboratories that provide all the necessary equipment and } \\
\text { virtual machines and provide experiments without any } \\
\text { expenses or financial burdens and save time and money to } \\
\text { fulfill any scientific or cultural requirements. }\end{array}$ & \\
\hline 3 & $\begin{array}{l}\text { Educational } \\
\text { services and } \\
\text { activities }\end{array}$ & $\begin{array}{l}\text { These services are provided by Virtual Reality City Center } \\
\text { professionally through Virtual Classrooms, bringing together } \\
\text { all students and learners in different areas of the city. The } \\
\text { teacher gives the lesson a much better virtualization than } \\
\text { distance learning through Video Conference which may be } \\
\text { less professional by Virtual Reality Because it allows the } \\
\text { student to carry out scientific experiments and the solution to } \\
\text { the teacher and is directed properly also there are many } \\
\text { educational activities that may be carried out by students in }\end{array}$ & \\
\hline
\end{tabular}




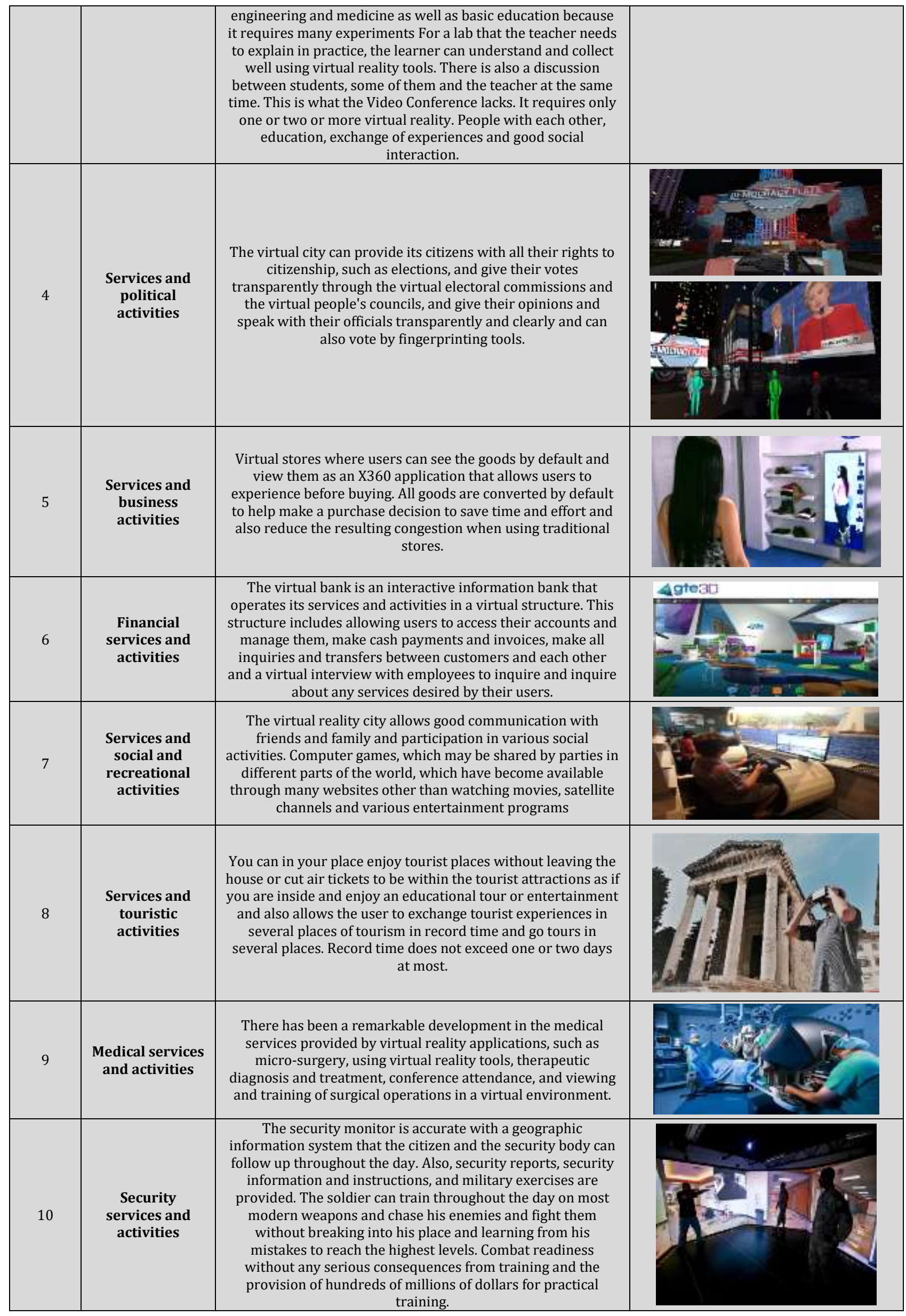


2.5.3 Advantages of the urban virtual city service center

1. Shared space: The virtual world allows many users to participate at once.

2. Graphical User Interface (GUI): VR provides a visual space; many 2D applications can be done as seen in animation or 3D as seen in immersive environments. It provides a broad base of modeling, installation, lighting and animation.

3. Socialization: Encourages the virtual world to form virtual assemblies' simulated worlds.

4. Collaboration: You can communicate with many individuals and institutions from around the world who share your interest in different fields.

5. Boundaries: You can work with people without limits (both temporal and geographic).

6. Interactivity: Many see that virtual reality is better than learning via video conferencing because you can use videos, presentations, images and external sites at the same time in one place. That means that you can easily create links between the world's activity and information resources in the real world.

7. Support: You can easily find people with the same problems, meet them, discuss your problems, and listen to the experts who attend the second life.

8. Learning: It is possible to involve a number of experts in any field who may be difficult to meet in normal life.

9. Search: You can search in magazines or browse the books in virtual libraries.

10. Exhibits: where you can hold exhibitions, video meetings or videoconferences.

11. Training and Simulations: With virtual world capabilities, virtual reality simulations can be created completely. The trainee can enter this experiment or scenario designed according to the nature of purpose. This is very useful in conveying the real reality before going down. Surgical operations - military sectors civil defense - practical experiments) .

12. Physical savings: where universities, classrooms and virtual buildings were erected if they were set up on the ground cost a lot.

13. The possibility of renewal and modernization: especially as the virtual reality depends on the technology is renewed and hasty.

14. The possibility of avoiding foreseeable risks in the real world, such as studying the nuclear reactor or piloting the plane and others.

15. Encourages creativity and innovation among users in programs that depend on creation, creation and manufacturing.

16. Allows users to carry out laboratory experiments step by step, as well as the opportunity to continue the experiment during an open period of time and using new techniques through the actual use of the experiment, and prepares the student to interact with the virtual experience and the positive participation in it according to the results obtained.

\subsubsection{Disadvantages of the urban services center of the} virtual reality city

1. The use of virtual reality is limited due to the excessive initial costs when purchasing the required equipment and the high cost of production of the virtual programs.

2. The limited impact of the five senses in the virtual reality system, which is used only in the sense of hearing, sight and touch, but may appear other developments that use other senses in the future.

3. Excessive use of virtual reality programs and computers has a negative health impact.

4. The use of special types of computer systems, which include the frequency of frames of moving images and more than fifteen frames per second, lead to injury to the individual nausea and headache and other symptoms such as fatigue and tension of the nervous system.

5. The virtual world places everyone in front of the whole world, giving it all ideas, creeds and bees. This increases the social and educational role, reduces the practice of guardianship, and undermines the idea of one opinion.

6. The tools that the user needs to wear on his head, eyes and hands, a problem researchers are seeking solutions to, including the US National Aeronautics and Space Administration borrowed a scene from the television series Star Trek, taking advantage of a "holographic surface" in which many people gather from distant areas for dialogue, exchange and discussion. The new idea lies in the use of holographic forms, stereographically generated by lasers, to transform a small hall into a "holographic surface" similar to a deck that people enter and feel part of the exciting reality surrounding them. NASA researchers are directing lasers and computers to generate threedimensional holographic shapes on the bottom walls to transform them into a unique location. Such halls were used in the production of the series "Flight of the Stars" "New Generation", where the crew used a similar hall for entertainment purposes.

\subsection{Virtual reality city}

Is a city that provides services to its citizens in administrative, cultural, scientific, educational, political, commercial, financial, social, tourism, medical and security services. It may have a basic function which is teaching, research, military or recreational, so the researcher imagines in a schematic manner as figure (8). 


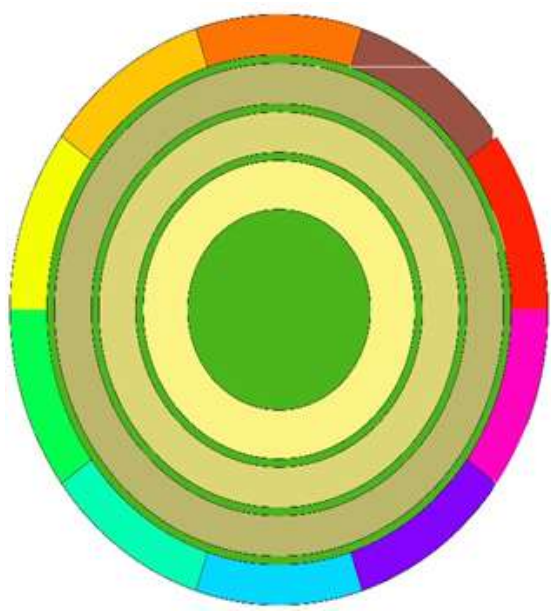

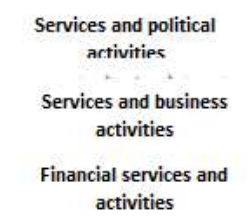

Services and social activities

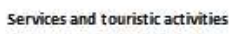

Medical services and activities

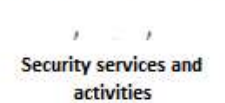

activities

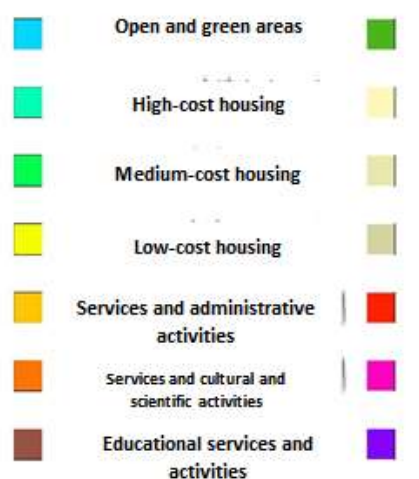

activities

Figure 8 Shows that the city is ideally planned in terms of distribution of green areas and vast urban areas with three levels of high, medium and low cost housing and 10 service centers on the outskirts of the city to help meet the needs of its citizens continuously

\subsection{Sustainability of urban life in virtual reality}

Although the main goal in planning a city is to meet human needs and reach a better level, we must not lose sight of the elements and indicators of urban sustainability so this part of the research discusses the extent to which the virtual reality city of sustainability is achieved.
Sustainability organizations sought to organize city planning projects to promote sustainability principles such as the American LEED, the British BREEAM, the Australian Green Star, and the Japanese CASBEE, from which the most important principles and principles were drawn, as shown in Table 2, it also illustrates the extent to which the virtual reality city has achieved these principles.

Table 2 Criteria derived from sustainability support systems

\begin{tabular}{|c|c|c|c|c|c|c|}
\hline $\begin{array}{c}\text { Foundations and } \\
\text { Principles derived } \\
\text { from Organizations } \\
\text { supporting } \\
\text { Sustainability }\end{array}$ & 풤 & 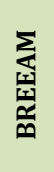 & 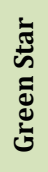 & 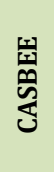 & 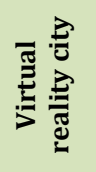 & Analysis \\
\hline $\begin{array}{l}\text { - Sustainability of } \\
\text { sites }\end{array}$ & $\sqrt{ }$ & $\sqrt{ }$ & $\sqrt{ }$ & & $\sqrt{ }$ & $\begin{array}{l}\text { Reduce carbon emissions within the city as a result of reducing the use of } \\
\text { vehicles. }\end{array}$ \\
\hline $\begin{array}{l}\text { - The efficiency of } \\
\text { water use }\end{array}$ & $\sqrt{ }$ & $\sqrt{ }$ & $\sqrt{ }$ & & $\sqrt{ }$ & $\begin{array}{l}\text { Virtual Reality City provides water as a result of reducing water } \\
\text { consumption using modern technologies within the city. }\end{array}$ \\
\hline - Energy Efficiency & $\sqrt{ }$ & $\sqrt{ }$ & $\sqrt{ }$ & $\sqrt{ }$ & $\sqrt{ }$ & $\begin{array}{c}\text { Virtual Reality City provides power consumption largely for virtual } \\
\text { reality tools from within the home. }\end{array}$ \\
\hline $\begin{array}{l}\text { - Recycling of } \\
\text { materials }\end{array}$ & $\sqrt{ }$ & & & $\sqrt{ }$ & $\sqrt{ }$ & $\begin{array}{l}\text { As a result of the use of virtual reality technology, the use of materials } \\
\text { decreases. }\end{array}$ \\
\hline $\begin{array}{l}\text { - The quality of the } \\
\text { internal environment }\end{array}$ & $\sqrt{ }$ & & & $\sqrt{ }$ & $\sqrt{ }$ & $\begin{array}{l}\text { The increasing number of green spaces, due to the lack of existing urban } \\
\text { centers, reduces vehicles and reduces environmental pollution }\end{array}$ \\
\hline - Innovation & $\sqrt{ }$ & & & & $\sqrt{ }$ & $\begin{array}{c}\text { The VR concept is based on innovation, development and constant } \\
\text { updating }\end{array}$ \\
\hline $\begin{array}{l}\text { - Providing pollution } \\
\text { control systems }\end{array}$ & $\sqrt{ }$ & & & & $\sqrt{ }$ & The city can control carbon emissions through virtual reality systems \\
\hline $\begin{array}{l}\text { - Provide natural } \\
\text { lighting and } \\
\text { ventilation }\end{array}$ & $\sqrt{ }$ & & & & $\sqrt{ }$ & $\begin{array}{l}\text { Attention to housing is a prerequisite for the success of the virtual city } \\
\text { system and its processing of all requirements of modern technology to } \\
\text { provide continuous service performance to its users }\end{array}$ \\
\hline - Optimal use of land & $\sqrt{ }$ & & & & $\sqrt{ }$ & $\begin{array}{l}\text { The abundance of green areas and o pen spaces due to savings in the } \\
\text { traditional services areas in the virtual cities }\end{array}$ \\
\hline $\begin{array}{l}\text { - Maintaining public } \\
\text { health }\end{array}$ & & & $\sqrt{ }$ & & $\sqrt{ }$ & Environmental pollution is less than in non-hypothetical cities \\
\hline $\begin{array}{l}\text { - Consider the nature } \\
\text { of the site }\end{array}$ & & $\sqrt{ }$ & & & $\sqrt{ }$ & $\begin{array}{l}\begin{array}{l}\text { Virtual cities allow innovative solutions to take into account the nature of } \\
\text { the sites because they do not require the status of the services except on } \\
\text { the periphery }\end{array} \\
\end{array}$ \\
\hline $\begin{array}{l}\text { - Sustainable waste } \\
\text { disposal }\end{array}$ & & $\sqrt{ }$ & & & $\sqrt{ }$ & $\begin{array}{l}\text { Using modern virtual reality technology, waste can be disposed of in a } \\
\text { sustainable way }\end{array}$ \\
\hline
\end{tabular}




\section{Conclusions and Recommendations}

1. The Virtual City is a city that provides services to its citizens in administrative, cultural, scientific, educational, political, commercial, financial, social, tourism, medical and security services. It may have a basic function of teaching, research, military or recreational, and the research has developed a vision for its planning.

2. Services and administrative activities, services and cultural and scientific activities, services and educational activities, services and political activities, services and business activities, services and financial activities, services and social and recreational activities, services and tourism activities, services and activities Medical, security services and activities.

3 . The research has reached the nucleus of the VRP, consisting of three levels of high, medium and low cost housing, open green spaces, and urban service centers on its outskirts.

4. Virtual city can deliver its urban services in a sustainable manner consistent with the elements of sustainability (sustainability of sites, water efficiency, energy efficiency, recycling of materials, internal environment quality, innovation, pollution control systems, natural lighting and ventilation, Land, maintaining public health, taking into account the nature of the site, disposing of waste in a sustainable manner).

5. Virtual science applications have helped to create an urban service center as a nucleus for a virtual city that can perform tasks to serve its citizens.

6. Discuss the research The most important pros and cons of implementing the virtual reality city as the most positive is the good social interaction as a result of communication with many individuals and institutions from all over the world share your interest in different fields and the most important disadvantages are the expensive initial cost when buying the required equipment and high cost of production of virtual programs.

7. One of the main findings of the research is that the virtual city has several urban functions that may be a military city, recreational city or educational, cultural or commercial city so that it can provide its services centrally according to its classification.

8. The research recommends the use of virtual reality technology, which helps the citizen to perform his tasks continuously without harming the environment or society.

9. Any discovery of a new technology shall indicate the maximum costs but when the cost is kept within the limits available, the research shall recommend the use of virtual reality technology and minimize the effects of using its tools.

10. To ensure the success of the virtual reality city, good training is required on its tools for its users and the processing of all its urban service centers with the latest technologies, tools and virtual environments required in order to achieve the highest degree of interaction with virtual experience and positive participation.

\section{References}

1. Boing company: Boeing Apache Helicopter Flight Simulators Provide High Fidelity Training www.boeing.com, Date: 27-7-2007, Available at: http://www.boeing.com/news/releases/2007/q3/070 727a_pr.html

2. Brandon, Medellin - City of Tourism and Eternal Spring, 2009, Available at: http://www.medellininfo.com

3. Buxton, W. \& Fitzmaurice, G.W. HMD's, Caves \& Chameleon: A Human-Centric Analysis of Interaction in Virtual Space, 1998

4. Campion, Andrew: Medellin Aerial Tram Giving Hope to The Barrios,17-12-2008, Available at: http:// www.themedellinblog.com/ Medellin aerial-tramgiving-hope-to-the-barrios

5. Dale, Steven: Medellin/Caracas, Part 2, www.gondolaproject.com, 12-3-2010, Avalable at: http://gondolaproject.com/2010/03/12/medellincarac as-part-2

6. Deering, Michael F.: Holo Sketch: A virtual reality sketching/ animation tool, 27-1-2010, Available at http://manojcst.blogspot.com/2010/01/holosketchvirtual-reality.html

7. Hassan, Ramzi: VR project of "Reconstruction of historical site of Hisham Palace in Jericho\ Palestine", Available at: http://vimeo.com/43809452

8. Hawkins, Tim: Medellin, 19-7-2010, Available at:http://tim1729.blogspot.com/2010/07/medellin.ht $\mathrm{ml}$

9. Hinds, Kate: Medellin Gets Mega Escalator, 28-12-2011 Available

at:http://transportationnation.org/2011/12/28/medel lin-gets-megaescalator/

10. Kevan, Tom: The Virtual Perspective/ New immersive systems harness the power of virtual reality to enhance design, promote collaboration, and reduce planning, 2 11-2007, at:http://www.deskeng.com/articles/aaafsr.htm

11. Keyser, Hogen: Virtual reality technology comes of age ,30-3-2012,Available at:http://www.telepresenceoptions.com/images/EON_i Cube.jpg

12. Navarro, Eleanor \& Smith ; Meliss, Adriana \&Paries: Article title:Brenner Fellowship Summary: Favela Chic 2-7-2011, Available at:124http://archinect.com/ features/article/104315/branner-fellowshipsummaryfavela-chic

13. Nicolago: Landscape of Como, 25-12-2008, Available at:http://it.wikipedia.org/wiki/File: Altocomo.jpg

14. Noguero, Franciso: Education of Medellin's Future Generation, 25-8-2008,Available at: http://medellincolombia.blogspot.com/2008/05/espanalirbrary-insanto-domingo.html

15. Saunter, Tom: Virtual Reality, Digital Cortex website, 30-5-2009, Available at: http://digitalcortex.net/ academic/ virtual-reality/\#.UM3yMuRf1nU

16. Sherman, William R. ; Craig, Alan B. : Understanding virtual reality, Interface, Application and design, Edition: 1, Publisher: Morgan Kaufmann, Publication, Pages: 608, 2002

17. Wikipedia, the free encyclopedia: Antioquia State, last update: 3-9-2017, Available at: http://en.wikipedia.org/ wiki/ File:Colombia_Antioquia_(1886).svg

18. Zid: Medellin Cable car System: Metro cable, 3-2016, Available at: http://www.skyscraperlife.com/ railsystems/1926-medellin-cable-carsystemmetrocable.html 